\title{
El censo consignativo en el pensamiento económico de la España Moderna
}

\section{J.L. PEREIRA IGLESIAS}

"Los labradores menesterosos sustentaban con sus flacas fuerzas todo el peso de la agricultura, y para conllevar su oficio cargaban censos y juros sobre las heredades, cuyos frutos no bastaban a pagar los gastos del cultivo, la renta, la contribución, los réditos y proveer el sustento de una modesta familia.

Maldecían los escritores políticos la iniquidad de hacer al censualista partícipe de la cosecha sin haber ayudado a la sementera ni correr el riesgo de los temporales, y en la exaltación de su odio a la tiranía del capital, según ahora se dice, condenaron los juros y los censos como causa principal de la ruina y miseria de los labradores, y pidieron una ley que declarase nulos semejantes contratos" (1).

Los censos cautivaron el intelecto de arbitristas, memorialistas y pensadores de los siglos modernos (2). Resulta de aquella seducción fue una plétora, sobre

(1) COlmeiro, M.; Historia de la Economía Política Española. Edición del Banco Exterior. Madrid, 1988, pp. 76-77.

En el memorial de peticiones y agravios que los labradores de Castilla elevan a Felipe II en el año 1553 se responsabiliza a los censos de la enajenación de mulas y bueyes por los campesinos.

Arbitrios muy importantes que tratan del crecimiento de foros y censos y otras cosas, los cuales van fundados en equidad, razón natural y justicia. Este memorial, que se guarda entre los manuscritos de la Biblioteca del Escorial, lo cita MONTES, J., Precursores de la ciencia penal en España. Madrid, 1911.

(2) La bibliografía sobre el pensamiento económico en la España de los siglos XVI y XVII es bastante amplia. Baste citar a: LAURES, J., The political economy of Juan de Mariana. Nueva York, 1928; VIÑAS MEY, C., El problema de la tierra en la España de los siglos XVI-XVII. Madrid, 1941; SAINZ RODRIGUEZ, P., Evolución de las ideas sobre la decadencia española. Madrid, 1948; SUREDA, J. L., La Hacienda castellana y los economistas del siglo XVT. Madrid, 1949; IPARAGUIRRE, D., "Las fuentes del pensamiento económico en España, en los siglos XIII al XVI", Estudios de Deusto, 2, 1954; IPARAGUIRRE, D., "Los antiguos economistas españoles y el desarrollo económico de España", Boletín de Estudios Económicos, 58, 1963; LARRAZ, J., La época del mercantilismo en Castilla, 1500-1700. Madrid, 1963; MARAVALL, J. A., Estado moderno y mentalidad social (siglos XV a XVI). Madrid, 1972; VILAR, J., Literatura y economía. La figura del arbitrista en el Siglo de Oro. Madrid, 1973; SIERRA BRAVO, R., El 
todo en las centurias del Quinientos (3) y del Seiscientos, de escritos censales que integraban los voluminosos tratados de economía moral redactados por teólogos y juristas españoles opinando acerca de la ética y licitud de los cambios, de los préstamos con interés y de la usura (4). Numerosos, pues, son los autores que de forma directa o tangencial se ocupan de los censos consignativos. Por imperativos de la brevedad mencionaremos algunos de los más notorios: Gregorio López Madera, autor del Discurso sobre la justificación de los censos; Cristóbal de Villalón: Provechoso tratado de cambios y contrataciones de mercaderes y reprobación de la usura (Valladolid, 1541); Fr. Luis de Alcalá: Tractado de los préstamos que passan entre mercaderes y tractantes; y por consiguiente, de los logros, cambios, compras adelantadas y ventas al fiado (Toledo, 1546); Fernando de Sevilla: Ordenanza que se ha de tener en las compras y ventas de los censos, según lo declararon los sumos pontífices Martín V y Calixto III (Guadalupe, 1547); Diego Pizarro: Tratado nuevamente hecho sobre los censos al quitar a manera de glosa (1548) y Tractado muy necessario y provechoso sobre los censos al quitar (Medina, 1551); Martín de Azpilcueta: Comentario resolutorio de usuras (Valladolid, 1565); Tomás de Mercado: Suma de tratos y contratos (1571); Antonio Gómez: Explicatio motus propius Pii V qui de censibus tractat (Alcalá, 1593); Feliciano de Solís: Comentarii de censibus (Alcalá, 1594); Cerdán de Tallada: Veriloquium en reglas de Estado según derecho divino, natural, canónico y civil

pensamiento social y económico de la Escolástica. Madrid, 1975; VILAR, P., Crecimiento y desarrollo. Barcelona, 1976; ALVAREZ VAZQUEZ, J.A., "Arbitristas españoles del siglo XVII", Cuademos Hispanoamericanos, 334, 1978; ABELLAN, J. A., "Orígenes del pensamiento económico y las ideas socialistas en España", Sistema, 40, 1981; CORREA CALDERON, E., Registro de arbitristas, economistas y reformadores españoles (1550-1936). Madrid, 1981; GRICEHUTCHINSON, M., El pensamiento económico en España (1177-1740). Barcelona, 1982; MARTIN RODRIGUEZ. M., Pensamiento económico español sobre la población. Madrid, 1984; GUTIÉRREZ NIETO, J. I., "El pensamiento económico político y social de los arbitristas", Historia de España. Tomo XXVI. El Siglo del Quijote (1580-1680). Madrid, 1986.

(3) Dicha producción intelectual se explica porque Castilla "pasó a ser en la primera mitad del siglo XVI el escenario privilegiado de los fenómenos económicos más importantes e interesantes de su tiempo".

SIERRA BRAVO, R., El pensamiento social y económico de la Escolástica. Madrid, 1975, p. 209.

(4) "Los primeros libros de Economía política que se publicaron en España son debidos a teólogos moralistas, quienes, con ocasión de hablar de la caridad, pasan a tratar de la limosna, del recogimiento de los pobres, de los peligros de la ociosidad, de la excelencia del trabajo, de los medios de fomentar la agricultura y las artes mecánicas, etc.; o ventilando la cuestión de la usura, examinan los tratos y contratos de los mercaderes, ponderan la grandeza de nuestras ferias, señalan los lugares de mayor contratación, enumeran los géneros y frutos que entraban y salian por las puertas de la aduana y discurren sobre la bondad o malicia de las leyes tocantes a esta materia de gobierno... Prosiguen la obra de los teólogos los jurisconsultos que, como versados en la ciencia del derecho, disertan sobre la potestad de los príncipes para imponer nuevos tributos, establecer tasas, alterar la moneda, enfrenar el lujo, impedir la entrada de las mercaderías extranjeras y la salida de los metales preciosos... Vienen en pos los escritores repúblicos lamentando la miseria de nuestros labradores, la completa ruina de las antiguas fábricas y telares de lana y seda, la desaparición de las celebradas ferias de Medina del Campo y otras partes, el poco fruto del comercio de España con las Indias Occidentales, la importación de las mercaderías extranjeras y la exportación del oro y plata. Investigan las causas de la riqueza de los Estados, reclaman protección y fomento para la 
$y$ leyes de Castilla (1604); Gaspar Rodríguez: Tractatus de annuis et menstruis redditibus (Medina, 1604); Federico Martín: Commentarius de iure censuum (Friburgo, 1605); Luis Vázquez de Avendaño: Tractatus de censibus Hispaniae (Alcalá, 1614); Mateo López Bravo: De rege et regendi ratione (Madrid, 1616); Luis Valle de la Cerda: Desempeño del patrimonio de Su Majestad y de los Reynos (Madrid; 1618); Jerónimo de Ceballos: Arte real para el buen gobierno de reyes $y$ príncipes y de sus vasallos (Toledo, 1623); Juan de la Ripia: Tratado de recaudación de las rentas reales (1624); Micer Jerónimo Ardid: Invectiva contra el vicio de la usura y usureros (Zaragoza, 1624); Antonio Josef Aoiz: Resolución a la duda ordinaria si es lícito al que presta dinero llevar nueve por ciento de intereses por lucro cesante (1627); Juan de Lugo: De los censos (Lyon, 1642); Luis Cencio: Tractatus de censibus (Lyon, 1658); José Llop: Expediente fácil y practicable para desempeñar y descargar la ciudad de Valencia de las muchas deudas que la oprimen, sustituyendo, en lugar de los censales a que boy responde, otros tantos censos temporales y vitalicios (Valencia, 1669); Lope de Deza: Gobierno Politico de Agricultura; Francisco Salgado de Somoza: Laberyntus creditorum (Lyon, 1672); José Alonso Ortiz: Ensayo económico sobre el sistema de la moneda-papel y sobre el crédito público (Madrid, 1746 ó 1796); Fernando González de Socueva: Estado actual de los censos más frecuentes en este Reyno y aquel a que deben reglarse sus réditos y condiciones (Sevilla, 1759); Vicente Vizcayno Pérez: Discursos políticos sobre los estragos que causan los censos, felicidades y medios de su extinción (Madrid, 1766); Conde de Cabarrús: Memorial al Rey sobre rentas y crédito público (1783); Josef de Salamanca: Parecer sobre la baja de los censos; Nicolás Gálvez, autor de una obra sobre el mismo asunto; Acosta Africano: Collación a los mohatreros, usureros, aparceros, tratantes y seducadores.

Teólogos y juristas condenaron o aprobaron el censo como instrumento de pago diferido (5). Podemos realizar un seguimiento de los principales discursos que a lo largo de los siglos XVI, XVII y XVIII se pronunciaron para condenar o afirmar la lícitud del censo al quitar (6). Para la corriente crítica los censos eran responsables del absentismo general y del abandono de las actividades producti-

agricultura y las artes mecánicas, solicitan leyes rigurosas contra el comercio fraudulento, anạlizan el valor de la moneda, imaginan planes de imposición, repartimiento y cobranza de contribuciones, proponen la fundación de erarios públicos o bancos de depósito adivinando la teoría del crédito $y$, en fin, inventan medios de restaurar las flacas fuerzas de la economía española. La ciencia económica asoma al horizonte desnuda ya de los ajenos atavíos con que antes se adornaba para mejor cautivar la voluntad de los hombres".

COLMEIRO, M., Biblioteca de los economistas españoles de los siglos XVI, XVII y XVIII. Madrid, 1979, pp. 8-10.

(5) La condena del interés se fundamenta en la idea de la esterilidad del dinero. Teólogos y moralistas sentencian que el dar a censo con sobrada bipoteca genera beneficios pecuniarios sin causa justificada, lo cual constituye usura. El capital deberá prestarse sin cobrar cantidad adicional de dinero porque se concibe como un acto de caridad para con el prójimo. Sin embargo, la inclusión del 'lucro cesante o el daño emergente permitirá a los propiós moralistas legitimar los préstamos disfrazando el interés de recompensa debida al prestamista por el riesgo que asume.

(6) En este artículo tan sólo haremos referencias a los principales autores que hicieron una valoración negativa del censo al quitar. 
vas (7). Entre los detractores se cuenta Pedro Fernández Navatrete (Conservación de Monarquias. Madrid, 1626), quien imputa a los juros y a los censos la despoblación del reino y la ruina de la agricultura:

"Demás de las causas que despueblan el reino, faltando en él la gente que le hacía tan lustroso y tan temido, hay otras particulares que convidan a los naturales de estos reinos a venirse a la Corte, desamparando su patria. Y aunque este daño ha sido común en todas las monarquías, ha cundido más en aquéllas donde la hacienda de los particulares se ha podido reducir a juros y censos... También se ha originado el abatimiento y desestimación de la agricultura de la invención de juros y censos ... porque, como en otro discurso queda ponderado, todos los ricos han puesto en ellos (como en hacienda holgazana) su caudal, dejando la labranza y crianza ... porque aunque los labradores no están faltos de la libertad natural, están siempre asidos al remo de tantos trabajos y necesidades; porque todo lo que adquieren con sudor, lo consumen en la voraz polilla de los censos, y en la paga de las mohatras y usuras, a que les compelen las necesidades... y así, mientras hubiere en las repúblicas juros y censos, no habrá estimación de la labranza" (8).

Acusaciones parecidas están en boca de Diego Pizarro (Tratado muy provechoso sobre los censos), del licenciado Gregorio López Madera (Discurso sobre la justificación de los censos), de Martín Azpilcueta Navarro (Comentario resolutorio de usuras, Salamanca, 1556), de Jerónimo de Ceballos (Arte real para el buen gobierno de reyes y príncipes $y$ de sus vasallos, Toledo, 1623), de Lope de Deza (Gobierno político de agricultura, Madrid, 1618) y de Mateo López Bravo (De rege et regendi ratione). Diego Pizarro aboga porque no se usaren los censos para así poblar los reinos de Castilla. Azpilcueta Navarro dice que son causa de los desórdenes que en nuestra España más crecen y Mateo López Bravo afirma que son más dañinos que la usura:

"Falta la holganza derivada de abusar del dinero; me refiero a la usura o al censo, peor que la misma usura. Este tipo de ocio es una invitación para todos, porque es considerado honroso, mientras que el primero, como deshonroso, aleja a muchos de sí. Además el mal de la usura fácilmente se vence por voluntad del que da o del que recibe, mientras que la enfermedad del censo es incurable... Porque nadie tiene interés en comprar y ocupar una finca cargada con tantas cargas y cuidados de acreedores... El censo es, pues, peor que la usura, porque inficionando cada día a más gente y de manera más grave, disminuye los negocios y aumenta el ocio" (9).

(7) "La animosidad hacia los juros y censos fue constante. En buen número de memoriales de arbitristas se hace la condena expresa de los mismos y la indicación de que el dinero invertido en aquellas dos formas crediticias debería utilizarse para la inversión productiva". GUTIERREZ NIETO, J. I., "El pensamiento económico político y social de los arbitristas", Historia de España. Tomo XXVI. El Siglo del Quijote (1580-1680). Madrid, 1986, p. 263.

(8) FERNANDEZ NAVARRETE, P., Conservación de Monarquías y Discursos politicos. Edición de M. D. Gordon. Instituto de Estudios Fiscales. Madrid, 1982, pp. 107 y 322-323.

(9) LOPEZ BRAVO, M., De rege et regendi ratione. Edición de H. Mechoulan. Madrid, 1977, p. 272. 
Y prosiguiendo esta breve andadura por la literatura económica y moral de los Siglos Modernos encontramos otras inculpaciones hechas por tratadistas relevantes. González de Cellorigo argumenta que los censos son la peste y la perdición de España; son responsables de la recesión demográfica y también de la destrucción de riqueza y de la atonía económica:

"La disminución y falta de gente ha muchos años que se siente en estos reinos... y todo procede de huir de lo que naturalmente nos sustenta. Y emprender lo que destruye las Repúblicas, cuando ponen su riqueza en el dinero y en la renta del que por medio de los censos se adquiere, que como peste general ha puesto estos reinos en suma miseria por haberse inclinado todos o la mayor parte a vivir de ellos, y de los intereses que causa el dinero, sin ahondar de dónde ha de salir lo que es menester para semejante modo de vivir. Esto es lo que tan al descubierto ha destruido esta República y a los que usan destos censos, porque atenidos a la renta se han dejado de las ocupaciones virtuosas de los oficios de los tratos de la labranza y crianza... De suerte es esto que se puede muy bien decir que la riqueza que había de enriquecer ha empobrecido, porque se ha usado tan mal della que ha hecho al mercader que no trate y al labrador que no labre... Mucho es lo que importa al Príncipe disponer las cosas de suerte que los suyos no se dejen llevar del error que siguen, y que entiendan los recién heredados y todos los vasallos que es engaño manifiesto fundar su riqueza en lo que hasta aquí y en vivir por cuenta de censos, cuyo uso convendrá reducir a término que pocos le apetezcan, porque el que hasta aquí se ha usado ha sido la peste y perdición de España. Y es que el mercader por el dulzor del seguro provecho de los censos deja sus tratos, el oficial desprecia su oficio, el labrador deja su labranza, el pastor su ganado, el noble vende sus tierras, por trocar ciento que le valían por quinientos del juro, sin considerar que habiendo dado todos en este trato la renta firme de la heredad se acaba y el dinero se va en humo. Porque uno que labra ha de sustentar a sí y al señor de la heredad y al señor de la renta, y al cogedor del diezmo y al recaudador del censo y a los demás que piden, y de ahí arriba se puede hacer cuenta que de la poca gente que trabaja a la que huelga sale a razón de uno por treinta... Con los censos casas muy floridas se han perdido y otras de gente baja se han levantado de sus oficios, tratos y labranzas a la ociosidad, y ha venido el Reino a dar en una República ociosa y viciosa y destruídose lo bueno, noble y antiguo de nuestra España, y engrandecídose lo peor de ella. Los censos sustentan un millón de ejecutores y a muchos hombres de mala conciencia que sólo sirven de destruir a los nobles y a todos los demás del Reino. Los censos son los que, anteponiendo a lo más ínfimo de la República a la ilustre y antigua nobleza de España, han puesto la monarquía en estado peligroso" (10).

(10) GONZALEZ DE CELLORIGO, M., Memorial de la política necesaria y ütil restauración a la República de España (1600). Edición de J. L. Pérez de Ayala. Instituto de Estudios Fiscales. Madrid, 1991, pp. 20-21 y 72. 
Los censos son "consumidores de las haciendas, estragadores de las fuerzas, destructores del tiempo, apagadores de la virtud, incentivos del ocio y oficina de toda maldad". Contribuyen a la multiplicación de activos amortizados y al estrangulamiento de la oferta de bienes inmuebles porque las cláusulas que estipulan los contratos censales señalan la prohibición expresa de enajenar la propiedad hipotecada; semejante interdicción tiene otros efectos inducidos: incremento de los precios así como de las rentas agrarias y urbanas y, por el contrario, disminución de los ingresos fiscales. Pero lo que deja de ingresar la Hacienda por este concepto repercute sobre los sujetos pasivos y sobre otros ramos sometidos a tributación: "Del uso de los censos, a quien tenemos hecho cargo del mal de nuestra República, hay infinitos daños, y entre otros porque en ellos se prohíbe la enajenación, que quita las permutaciones y traspasos por pacto expreso, para poder usar de la vía ejecutiva aunque la hipoteca esté en tercero poseedor, y también porque estorban las compras y ventas en daño del Príncipe y del común de todos los estados. De lo cual se sigue que el Rey pierde mucha parte de sus rentas, y parte de lo que en esto falta lo suple el común en sus encabezamientos y en los demás impuestos". Incluso, dice González de Cellorigo, los censos que se imponen sobre fincas y demás bienes raíces restan incentivos a los posibles compradores de tales activos: "huyéndolos todos de comprar bienes hipotecados y acensuados, se suelen las tierras labradas antes perder que haber quien quiera entrar en ellas y darles las labores necesarias" (11). Cellorigo, a diferencia de otros arbitristas y memorialistas, no aconseja soluciones traumáticas: "No conviene usar de remedios violentos para restaurar esta República". Entre las medidas de política macroeconómica que a su juicio se habrían de tomar para reactivar la economía e incrementar la riqueza del país figuraba la amortización de los censos "más bajos en precio y más crecidos en rédito". Cellorigo es consciente de que los tipos de interés tienden a bajar cuando aumenta la oferta de dinero en circulación: "suelen bajar los intereses cuando hay mucho dinero". También proponía la revisión del precio del dinero para abaratar los tipos de interés y frenar de este modo la galopante inversión de capitales en activos financieros:

"Esto es pretender concluir que, para remediar el daño de los censos, de suerte que no dañe, conviene que el desempeño del Príncipe comience con el socorro de los ricos... y que, desde alli, se vaya haciendo en los tributos e impuestos que más agravan a los súbditos recompensa, quitando al patrimonio real los censos más bajos en precio y más crecidos en réditos, introduciendo un precio acomodado en los que quedaren de una vez para otra, de suerte que no se perturbe el estado ni haga demasiado sentimiento... podrase suavemente conseguir lo propuesto disponiendo el estado de la República de suerte que los censos vayan perdiendo de su valor y los bienes raíces le cobren... en comenzando a bajar los intereses de los censos, conviene luego pasar a dar forma acomodada a los cambios de entre los naturales, porque, en faltando la corriente de los intereses de los mismos censos y represándose el dinero que procediere de las redenciones de ellos, es fuerza que han de acudir muchos a hacer sus empleos lo mejor que puedan" (12).

(11) Ibid., p. 173.

(12) Ibid., pp. 175-177. 
Lope de Deza menciona a los censos al quitar entre las diez causas de la carestía y falta de labradores en España. "La cuarta razón de la falta de los labradores y de la carestía de los frutos es su consecuencia; es la muchedumbre de censos que se han impuesto e imponen cada día, siendo ya ésta una generalísima manera de vivir en España, pero de tan general perjuicio como ella es general" (13). Deza tiene palabras muy duras para con el censo como instrumento de crédito y área de inversión, para con sus condiciones y para con las hipotecas:

"En el censo hay aquella carcoma que de día y de noche está royendo, que aquel mismo día que paga empieza a deber, que los plazos se apresuran de manera que parece se alcanza uno a otro, y si se descuida el acensuador, como de industria hacen muchos, mayormente en censos pequeños, remanécen de mayor suma los corridos que el principal. Extraña cosa que de los cien ducados que tomó el bisabuelo a censo se hayan pagado doscientos y trescientos, y deba el bisnieto los mismos cien ducados y los réditos de ellos... Lo otro, el tomar a censo, es un mal encubierto, que no se deja entender hasta que no tiene remedio, porque en el supuesto de que no les pueden pedir el principal, les facilita engañosamente todo lo demás y por sólo este anzuelo encubierto de este cebo está 'perdido el miedo totalmente de tomar a censo, y es el escorpión que halaga con la boca y pica con la cola, de suerte que si pudieran permitirse las usuras, sin comparación fueran menos los perdidos por ellas que por los' censos por sola esta facilidad de tomarlos con que se toman por cualquier ocasión y aún sin ella.

Lo otro es gran inconveniente la perpetuidad de los réditos y el estar siempre sin libertad las personas y las haciendas para poderse aprovechar de ellas vendiéndolas, donándolas, dividiéndolas...' Acerca de las hipotecas hay también que considerar por qué si se dan trescientos ducados se han de obligar mil de hacienda" (14).

(13) LOPE DE DEZA, Gobiemo Político de Agricultura. Ediciôn de A. García Sanz. Instituto de Estudios Fiscales. Madrid, 1991, pp. 53-54.

(14) Opinión extendida era considerar al censo consignativo como usura porque se percibía una cantidad adicional de dinero por el principal prestado. $Y$ el interés, es decir, el beneficio sobre el capital, según Lope de Deza, es usura: "es usura una suerte principal de dineros prestada, con que sin intervención de trato alguno o grangetía se ganan otros dineros... Síguese ahora el saber qué es censo qué dicen al quitar y hallaremos que es una suerte principal de dinero dado a un tercero, con intervención de una venta de tantos maravedís que hace y constituye de renta sobre tal y cual hacienda suya en cada año sin poder ser ejecutado por el principal hasta que de su voluntad quite, pagando cada año la usura que aquella suerte principal monta, que en esta significación usura y censo suenan lo mismo". LOPE DE DEZA, op. cit., pp. 54-56 y 57-58.

Así como para teólogos y moralistas el interés o rendimiento del capital es usura, para los economistas la legitimidad clel interés se fundamenta en "la virtud productiva del capital y el sacrificio del goce presente por la abstinencia del inmediato consumo... la usura o el interés del 'capital es un acto tan conforme a la razón y a las leyes como vender una tierra o arrendar una casa". La consideración del interés como usura se fundamenta en la creencia de la esterilidad e infructuosidad del dinero y, desde este punto de vista, la percepción de una suma adicional sobre el capital prestado es injusta. El argumento que justifica el interés, en opinión de teólogos y moralistas, es el lucro cesante o el daño emergente.

COlMEIRO, M., Historia de la Economía Política Española. Edición del Banco Exterior. Madrid, 1988, p. 311. 
Deza juzga que los censos al quitar pudieran ser provechosos para tratantes y mercaderes, mas no para los labradores: "el daño que causa en la agricultura que hace a nuestro propósito es gravísimo... Porque como los réditos se pagan cada año uniformemente, y dinero y los frutos faltan por diversos accidentes, ni el que da el censo lo labra, porque no es suyo, ni el que percibe, porque no puede acudir a todo, habiendo de pagar áun cuando a él no le acude... Y por esto es muy poderosa causa esta de la falta de labradores y carestía" (15). Como buen arbitrista, Deza propone una serie de remedios para curar la grave enfermedad que aqueja a la agricultura española. Y entre la terapia que aconseja se incluye la reforma parcial del mercado crediticio y financiero español: prohibir la compraventa de nuevos censos y rebajar la tasa de interés de los ya contratados; revitalizar la vieja institución de la enfiteusis; amortización de los censos al quitar una vez que el prestatario haya abonado intereses por valor del capital que recibió a crédito; impedir a los labradores que puedan tomar dinero a censo y que dispongan de sus bienes raíces para avalar las hipotecas.

Sancho de Moncada y Caxa de Leruela se muestran más moderados en sus críticas a los censos que González de Cellorigo y Lope de Deza. Moncada inicia sus Discursos con la exposición de las diversas causas que se argüían en su tiempo para explicar la decadencia de España: "La quinta causa dicen que es haberse dado todos a tener renta, y quitado la labor, comercio y oficios, grave daño... Pero no es daño radical. Lo primero, porque son los juros y censos muy antiguos, y el daño muy fresco. Lo segundo, porque todos apetecen renta, porque es cosa más segura, y de ordinario de más útil que las demás cosas de comercio y oficios" (16). Participa de la opinión de sus coetáneos al atribuir la recesión de la actividad productiva y la caída de los ingresos de la Hacienda Real a la holgazanería. Ociosidad que se ve favorecida por la importante expansión del mercado de juros y censos, hasta el punto de propiciar el desarrollo de una mentalidad fundada sobre la especulación y la renta financiera:

"España está muy en el discurso del perezoso, más vale un poco de renta en paz que mucha hacienda con cuidado. Los daños de esto son muchos. El primero, que los ricos y los pobres fundan ya su vivir en renta, y siendo los censos no más que un poco de papel, no tienen otro ser que el ser de los bienes en que estriban, y como faltan los bienes, faltando la labor, crianza, comercio y oficios dan con el censo en el suelo; y así se ve la falta que tienen por ellos las rentas Reales, los labradores, y generalmente todo el reino hasta que obligaron a V. Majestad a subirlos a veinte.

A algunos ha parecido que importaría subirlos más, porque, viendo los réditos tan cortos, empleasen las haciendas en comercio, labranza y crianza. Pero no conocen lo que esto dicen la holgazanería que hoy tiene España, y no querrán sino renta, aunque perezcan.

El remedio es ejecutar el discurso primero, con que será mucho mayor, y más seguro el aprovechamiento de las demás cosas que el de los

(15) LOPE DE DEZA, op. cit., pp. 59-60.

(16) SANCHO DE MONCADA, Restauración Política de España. Edición de J. Vilar. Instituto de Estudios Fiscales, Madrid, 1974, pp. 100-101. 
juros y censos, y emplearán en ellas sus' haciendas, que hoy emplean en juros y censos, porque hallan las demás cosas de poco útil, y mucho riesgo" (17).

Los remedios que Sancho de Moncada enumera en el Discurso Primero rezuman el espíritu proteccionista del mercantilismo de la época: que las rentas se concedan únicamente a españoles; que "solos españoles usen artes y oficios en ella"; que no se saquen de España mercancías vedadas por ley y que se prohíba la entrada de productos elaborados procedentes del extranjero (18). No obstante, Moncada reconoce como serio obstáculo para el éxito de su programa económico la gran suma de capitales dados a censo por instituciones eclesiásticas y fundaciones piadosas: "La dificultad que se puede ofrecer es que los juros y censos son de importancia a muchas religiones, cofradías, hospitales, y viudas que no pueden acudir a beneficiar sus haciendas de otra manera" (19).

Caxa de Leruela piensa que la etapa de recesión por la que atraviesa la economía española se debe a la falta de ganados y no tanto a la abundancia de los censos: "son muchísimos los que tienen sobradas heredades con las cuales, 'y muchas menos, sus padres vivieron ricos y sustentaron caballos y lustre; y ahora, aunque se ayuden de algunos réditos, no pueden sustentar la labor si no tienen ganado; y lo más general es la imposibilidad de conservarlo, por la necesidad de los pastos... se colige, que es otra la causa de daños tan generales, y que nó es la ociosidad de la miseria y pobreza de los que continúan el trabajo y cultura de la tierra, ni los censos, juros, vínculos y mayorazgos... y si aquellas causas no se atajan, aunque los censos y juros suban a cuarenta, no será posible establecer la crianza de los ganados, ni instruir la labranza perfectamente" (20).

Finalizamos este sucinto recorrido por la fecunda literatura de pensamiento económico y moral, impresa en los siglos XVI, XVII y XVIII, que concibió el censo consignativo como un obstáculo para el desarrollo económico de la España Moderna, con uno de sus mayores detractores: Vizcaíno Pérez. El Licenciado Don Vicente Vizcaíno Pérez, Abogado de los Reales Consejos, es autor de los Discursos politicos sobre los estragos que causan los censos, felicidades y medios de su extinción, editados en Madrid por la Imprenta de Antonio Marín, en el año 1766. Vizcaíno Pérez responsabiliza a los censos consignativos de la ruina del Estado y de las tensiones inflacionistas que soporta la economía castellana, al constituir una de las principalísimas causas de la carestía de todos los comestibles y utensilios necesarios a la conservación y comodidad de la vida humana. $\mathrm{Y}$ por esta razón ruega a los acaudalados que no inviertan sus ahorros en semejantes activos y a los necesitados que no empeñen sus haciendas con dichos créditos hipotecarios. "Para esto -afirma- he procurado hacer algunas demostraciones de los estragos espirituales y políticos que este contrato ha causado $y$

(17) Ibid., pp. 102 y 208.

(18) Ibid., pp. 102-122.

(19) Ibid., p. 208.

(20) CAXA DE LERUELA, M., Restauración de la abundancia de España. Edición de J. P. Le Flem. Instituto de Estudios Fiscales. Madrid, 1975, pp. 57-58. 
causa a unos y a otros; y los medios de precaverlos sin perjuicio de ninguno" (21).

Vizcaíno Pérez es conocedor de la literatura político-económica que, desde generaciones pasadas, viene pregonando con obstinación los males de la sociedad española: "Muchos se han fatigado en descubrir las causas de la decadencia, despoblación, esterilidad y carestía insoportable de España; y proyectando arbitrios para su remedio han dado al público voluminosos libros y curiosos impresos... Trátase en los que yo he visto de extinguir las rentas provinciales y millones, suponiendo, y con razón, ser la ruina del Estado. Otros la atribuyen a la escasez de gente por las familias que pasan a los Reinos de Indias, y hacen falta para la labor, manufacturas y procreación en nuestra Península. Algunos a la multitud de religiones y aumento de religiosos y a el crecido número de eclesiásticos seculares; muchos a la falta de ganado lanar y demás especies; y otros, finalmente, a el demasiado plantío de viñas". No obstante, Vizcaino Pérez tiene sus propios argumentos y achaca la decadencia a la carestía de los bienes de consumo primarios: "Discurre mi cortedad que el principalísimo motivo de nuestra miseria es la carestía de los comestibles". Los efectos inducidos de esta coyuntura alcista parecen estar claros para nuestro personaje: "la imposibilidad de sostener las labores, a que se sigue el abandono, y de esto, el que todos buscan otro modo de establecerse; unos se hacen eclesiásticos, otros se acogen a la clausura para asegurar su subsistencia, otros se ausentan a Indias y países extranjeros, y muchos huyen y se abstienen del estado del matrimonio porque no pueden mantener las obligaciones que le son consiguientes; de modo que la carestía de los comestibles es el principio y el fin de nuestra decadencia; y así, el que halle arbitrio para remediarla se podrá justamente apellidar Restaurador de España".

¿Por qué se han encarecido tanto los bienes de consumo? Según el juicio de Vizcaíno la responsabilidad recae sobre los censos: "Si no me engaña el discurso y la experiencia, la más especial y casi original causa de toda la carestía que padece el Reino son los censos... los censos son la causa de la escasez de granos y de las alteraciones en los precios de todas las cosas". Vizcaíno Pérez no se limita a averiguar la naturaleza del mal, sino que, cual si de un arbitrista del siglo XVII se tratase, propone la terapia necesaria para erradicar la enfermedad: "El Reino es un cuerpo político cuya cabeza es el Soberano y su justicia; los brazos la milicia y el comercio; y los pies la labranza y cría de ganados. Estos dos merecen la primera atención, sin que falte a aquéllos, porque un cuerpo sin robustos pies no puede tener mucha fuerza en los brazos para defender la cabeza... Yo trato en este breve Discurso... de curar el cáncer que ha corroído no sólo los pies de esta Monarquía, labranza y cría de ganados, sino también el brazo del comercio y aún el de la milicia, pues sólo ha quedado ilesa la cabeza".

La antipatía de Vizcaíno Pérez hacia el censo consignativo es tal que no duda en relacionar el inicio de la decadencia española con la introducción del

(21) El manuscrito de Vizcaíno Pérez se halla depositado en la Biblioteca Nacional. Nosotros hemos manejado la reproducción microfilmada que amablemente nos facilitó la mencionada institución. Signatura 3/12835. 
contrato de censo en el Reino, allá por el año 1350 (22): "Las riquezas y abundancias que había en nuestra península antiguamente empezaron a decaer, según refiere el Bachiller Valverde Arrieta en su Dispertador Político, desde el tiempo del Rey, Don Pedro, que entró a reinar en el año de 1350 . Y en este tiempo, o poco después, se empezó a conocer en España el contrato de censo".

Vizcaíno no cuestiona la licitud del censo y orienta su discurso hacia los perjuicios políticos, económicos, sociales y morales que ocasiona esta fórmula de crédito. Los censos consignativos son culpables de estelionato. Tal fraude se intentó corregir con una mayor transparencia informativa en materia censal. En la Ley III, del Título Quince, del Libro Quinto 'de la Nueva Recopilación se establece la siguiente obligatoriedad: "Por cuanto nos es hecha relación que se excusarían muchos pleitos sabiendo los que compran los censos y tributos, los censos e hipotecas que tienen las'casas y heredades que compran, lo cual encubren y callan los vendedores, y por quitar los inconvenientes que de esto se siguen, mandamos: que en cada ciudad, villa o lugar donde hubiere cabeza de jurisdicción, haya una persona que ténga un libro en que se registren todos los contratos de las calidades susodichas" (23). Sobre el mismo asunto insistiría en 1713 Felipe $\mathrm{V}$, consciente del incumplimiento de la ley: "todo lo cual cesaría si rigurosamente se hubiese observado, como debía, dicha ley" (24). Además, los censos "son hijos y padres de la ociosidad, madre de todos los vicios" (25). Fomentaron el absentismo entre las clases adineradas porque los ahorradores, frente al riesgo de otros negocios inversores, encontraron en la compra de censos la seguridad necesaria para rentabilizar sus capitales:

"Conociendo, pues, su astucia en los ociosos una materia dispuesta a todo género de excesos, indujo a los hombres a la ociosidad, separándolos de la honesta ocupación y trabajo. Y ellos bien hallados, sin el cuidado de los negocios y comercios, discurrieron arbitrio para vivir con descanso y asegurar sin contingencia rentas para su fausto y alimento. No encontraron ni pudieron encontrar medio más proporcionado para lograr por su vida y vin-

(22) La antigüedad del 'censo queda recogida en varios testimonios documentales como las Bulas de Martín V (1420), Calixto III (1455), el Motu Propio de Pío V (1569) y la legislación que sobre dicho particular establecieron las Cortes de Toro de 1505: "Si alguno pusiere sobre su heredad algún censo con condición que si no pagare a ciertos plazos, que caiga la heredad en 'comiso, que se guarde el contrato y se juzgue por él, puesto que la pena sea grande y más de la mitad".

Cortes de los Antiguos Reinos de León y de Castilla, Edición de la Real Academia de la Historia. Madrid, 1882. Tomo Cuarto, p. 214.

(23) Recopilación de las Leyes destos Reynos, becha por mandado de la Magestad Católica del Rey don Felipe Segundo nuestro señor; que se ba mandado imprimir, con las leyes que después de la última impressión se han publicado, por la Magestad Católica del rey don Felipe Quarto el Grande nuestro señor. Año 1640. Edición facsímil. Editora Lex Nova. Vol II. Valladolid, 1982 , p. 42.

(24) Autos Acordados, Libro Tercero, Titulo Nono, Auto Acordado XXI. Edición facsímil. Editora Lex Nova. Vol. IV. Valladolid, 1982, p. 383.

(25) Vizcaíno cita a Fernando Matute de Azevedo, quien en su obra, El triunfo del desengaño (Nápoles, 1632), hermana a la ociosidad con la pereza, el vicio, la ruina de la sociedad y del Estado, la pobreza, la enfermedad, la lascivia, la quiebra de la hacienda y la pérdida del honor. 
cular en sus sucesores estas aparentes y perjudiciales felicidades que la creación de los censos, pues con ellos consiguieron mantener sus caudales sin disminución, coger los frutos sin trabajo, vivir sin ocupación y perpetuar en su familia un aborrecimiento a la industria, cuidado, afán y fatiga que nos dejó por herencia el primer hombre".

No le falta razón a nuestro autor cuando afirma que los mayores demandantes de censos consignativos son "las personas más poderosas y hacendadas, las Comunidades, las Iglesias, Hospitales y Obras Pías". Como antes se dijo, estas instituciones preferían buscar la seguridad de las rentas sobre el capital antes que asumir riesgos innecesarios: "Es constante que todos anhelan a tener sus rentas en censos o juros, porque sobre estar siempre existente su dinero en el capital, les produce un tres por ciento, sin los riesgos de las excesivas o escasas lluvias, escarchas o hielos, sin el peligro de la mala grana, sin la contingencia de que le coman los frutos los ganados... sin los azares de un incendio o terremoto, de una inundación o huracán, piedra o langosta; porque aunque esto suceda, no les comprende a los censualistas, pues quedando las fincas, o parte de ellas, subsiste su censo y cobra sus réditos".

Otra crítica muy severa que Vizcaíno Pérez hace contra el censo al quitar o redimible es la relativa a la inexistencia de períodos ciertos de amortización del principal. La redención o devolución del capital se hacía en un único plazo y a voluntad del prestatario y, hasta que ello no sucediese, los intereses debían abonarse en la fecha fijada en el contrato notarial:

"En el censo hay aquella carcoma que día y noche está royendo la hacienda y la industria del que la ha de pagar, pues en el mismo instante que satisface el rédito devengado, empieza a deber... ¡Extraña cosa que de 100 ducados que tomó el bisabuelo se hayan pagado 200 ó 300 y deba el biznieto los mismos 100 ducados y los réditos de ellos!". La obligación por parte del prestatario de ofrecer garantías hipotecarias superiores al valor del principal también fue motivo de críticas por este insigne jurista: "No causa menos violencia creer que los censos son ventas... viendo que para 300 ducados que hayan de dar para socorrer la necesidad del que los toma, ha de obligar mil de hacienda, cuando en el contrato de compra verdadero, con dar una heredad que valiese los 300 ducados salía de su ahogo... Yo, a la verdad, no encuentro donde está la equidad de este contrato".

Los censos son los causantes de la quiebra de muchas haciendas patrimoniales: "Digo que son la destrucción de las haciendas, pues en hallándose los hacendados en algún ahogo o necesidad de dinero, recurren al inmediato remedio de imponer un censo; y como hallan infinitos que les brindan con él, no se detienen en abrazar esta carga, porque les es muy dulce el tomar; y como entonces nada les piden, no se acuerdan del rédito que después han de satisfacer". Vizcaíno Pérez nos delata la falacia que esconden numerosos contratos censales porque, al propiciar el fingimiento de riquezas, ocultan la verdadera honra y estima social: "No sucede ni se nota esto constituyendo censos, porque como se quedan siempre con el dominio de la alhaja, y por entonces no muda de dueño, y éste ignora el perjuicio que se hace, y no llega a noticia del público, se determinan a empeñarse más y más cada día; y aunque parece que tienen cuantiosas haciendas, son hipócritas sus caudales, siendo en realidad de los acreedores censualistas". 
En opinión de nuestro insigne tratadista, los censos consignativos son contraproducentes para la buena marcha de la economía nacional porque contribuyen al aumento de los niveles de consumo por encima de las posibilidades reales del gasto privado y público, llevando a labradores e instituciones a una espiral de endeudamiento progresivo; son culpables de la decadencia del sector agrario español; encarecen las rentas de los alquileres urbanos y los precios de bienes de consumo tan necesarios como las carnes, los granos y las manufacturas; favorecen el aumento de las tasas de celibato forzoso y la disminución de las segundas nupcias; son responsables del crecimiento de las bolsas de pobreza empujando a muchos menesterosos a la mendicidad, al delito, la prostitución y la picaresca (26).

"Aquél que quiere ostentar su vanidad en alguna magnífica función, o el que intenta hacer alguna conquista para sus apetitos, no se detiene en contraer deudas; y estrechando después sus acreedores, se ve precisado a gravar su hacienda con censos... se determinan a empeñarse más y más cada día; y aunque parece que tienen cuantiosas haciendas, son hipócritas sus caudales, siendo en realidad de los acreedores censualistas... El segundo perjuicio que se sigue de los ocultos empeños y disfrazadas deudas de los censos es que cuando llegan a fallecer los maridos, creyendo las mujeres que quedan con lo necesario para poder vivir en honesta y decente viudedad, o pasar a segundas nupcias, descubren tantos acreedores que aún no pueden reintegrarse de su dote, por cuyo defecto no se casan, aunque queden jóvenes; y dificultándose de este modo la lícita procreación, se origina la falta de gente que se experimenta en España... El tercer perjuicio que ocasionan los censos es que si se imponen sobre casas, acostumbrado el dueño de ellas a percibir de sus alquileres 2.000 reales, por ejemplo, cada año, aumenta el precio del arrendamiento en la primera ocasión para que no se le disminuya su regular producto con los réditos del censo... Si llega a estar decadente por la falta de una o dos cosechas, antes de enajenarse de alguna de sus propiedades, las grava todas con censos. Llega después otra cosecha, y si vuelve a ser estéril, sobre no sacar los gastos de la labor, se imposibilita más con los réditos del censo que tiene que pagar, y tal vez se ve necesitado a imponer otro... Perdido este aldeano por el concurso que le ocasionaron las ejecuciones de los censos, falta este labrador o menestral y se encarecen los granos, las carnes y manufacturas cada año más... Viéndose estos concursantes sin arbitrio para volver a la labranza... se hallan en la última necesidad, y no tienen otro remedio que pedir limosna o destinarse al robo... por lo regular, se retiran estos miserables a las capitales o a la Corte, donde abunda el dinero, no falta la caridad y sobran conventos en que dan de comer".

(26) Su aguda crítica contra los censos consignativos le lleva a retomar prácticas económicas tradicionales, pues aboga por el retorno a la economía del trueque: "Lo menos necesario (no digo inútil) en un Reino para su gobierno político interior es el dinero... pues en teniendo las cosas necesarias para el sustento de los habitadores, no es tan precisa la moneda, porque pasariamos sin ella, como antes que se inventase, con las conmutaciones de unas cosas para otras, según se practica en algunos lugares de España". 
Estas y otras razones llevan a Vizcaíno Pérez a solicitar que los intereses impagados no recaigan sobre los herederos: "Mucha utilidad experimentaría la causa pública si como hay leyes que mandan se prescriban y acaben las acciones por cierto tiempo... las hubiese también para la prescripción de los réditos de los censos por cierto número de años, estableciendo en el poseedor de la hipoteca la responsabilidad de los adeudados en su tiempo solamente".

Igualmente, Vizcaíno Pérez culpa al censo consignativo del aumento del desempleo en la economía española. Cual si de un aritmético político se tratase, calcula que al año se destruyen en el sector primario 21.175 empleos: "Supongamos que en cada pueblo se pierde un labrador cada año, computando unos con otros. Habiendo, como hay, 21.175 pueblos en España, vienen a perderse al año 21.175 labradores. Esta es una sangría que ha de debilitar mucho el cuerpo político de la Monarquía; y aunque se dediquen a otros oficios mecánicos, los granos que la industria y trabajo de éstos producía, han de hacer falta para la manutención del Reino, y han de ser caros los mantenimientos". Y, a continuación, apoya sus estimaciones numéricas en los indicadores que le proporciona la Unica Contribución. Cifra el importe global de los réditos ingresados por los censualistas en 68 millones de reales: "Según el examen de productos de las haciendas, así de Legos como de Eclesiásticos, executado de orden del Señor Rey Don Fernando VI para establecer la Unica Contribución... resulta que el estado eclesiástico de las veinte y dos Provincias de Castilla y León percibe de réditos de censos por lo Beneficial 29.713.667 reales, y por lo Patrimonial, 1.106 .032 reales, y que los Legos cobran 12.373 .639 reales, que en todo componen 43.193 .338 reales, cuyo capital importa 1.439.777. 933 reales. Y no estando comprehendidos en esta averiguación los censos que hay en los reinos de Aragón, Cataluña, Valencia, Vizcaya y Navarra, y los muchísimos posteriormente creados en la Corte, bien podremos regular otra tanta cantidad... sacamos que en España se pagan de réditos anualmente 68.386 .676 reales cuyo capital asciende a 2.879 .555 .866 reales". Unas páginas más adelante vuelve a insistir acerca del importante volumen de negocios que mueven los censos dentro del mercado crediticio español:

"Con dificultad creerán los que vean este manifiesto, que está empleada en censos más de una cuadragésima octava parte de todas las haciendas de España... a los Legos les produce anualmente las tierras, los ganados de todas especies, las casas, artefactos y edificios, la industria y el comercio, sin incluir los jornales y salarios (porque esto no es producto de las haciendas, sino de las personas) 1.799.211.776 reales. A los Eclesiásticos les producen estas mismas clases de haciendas, sin incluir lo Beneficial, 310.514.365 reales; que ambas partidas suman 2.109.726.141 reales. Lo que reditúan los censos asciende a 43.193.338 reales, que es menos de una cuadragésima nona parte de lo que producen todas las haciendas; luego se verifica mi antecedente proposición".

De enorme interés son sus tres Demostraciones. A saber: Demostración de lo que produciria el dinero que está empleado en censos si se bubiese destinado o destinase lo que falta que imponer en cría de ganados; Demostración de lo que produciría el dinero que está empleado en censos si se bubiese destinado a la cultura de los campos o construcción de edificios; Demostración de lo que produciría el dinero que está destinado a censos, depositado y detenido para este fin, si se probibiese este contrato y se emplease en comercio. 
Respecto a la primera Demostración, entiende nuestro tratadista que el efectivo colocado por los inversores en operaciones de crédito a corto y largo plazo es perjudicial al sistema productivo; por tanto, procede su reinversión en otras actividades mercantiles: "Si los 2.879.555.866 reales que por lo menos están impuestos en censos, se emplearan en ovejas, se podían comprar a el respecto de 20 reales cada una, 143.977.793 cabezas". Este incremento de la cabaña ganadera redundaría en beneficio de sus propietarios y de la Hacienda. Evalúa los impuestos que tributa cada cabeza de ganado en 6 reales y medio al año: "las 143.977 .793 cabezas, si las hubiera en España; producirian para el Real Erario anualmente 863.866.758 reales". Y este aumento de los rebaños proporcionaría trabajo a un colectivo importante: "En pastorear esta numerosísima copia de ganados se emplearían 719.380 personas". Se remediarian de esta forma el desempleo y el subempleo que, por las aventuradas estimaciones de Vizcaíno, afectaba a 1.377 .358 personas. Refiere también que, según el repartimiento de quintas del año 17,62, había en los 12.979 pueblos de las 22 provincias de Castilla 1.632 .376 vecinos pecheros; en los reinos de la antigua Corona de Aragón 485.351 vecinos y en Navarra y Vizcaya 50.000 vecinos. Lo cual hace un total de 2.167 .727 vecinos; y, "considerando 5 personas por vecino como prudencialmente se estima", suman 10.838 .635 almas. Añádanse 180.319 eclesiásticos y 160.000 militares y sumarán 11.178 .954 personas. "Aun cuando la mitad sean mujeres, quedan 5.589.477 varones; de éstos considero que habrá 1.088.863 muchachos, regulando a uno por vecino; con cuyo desfalco queda reducido el número de hombres útiles a 4.500 .614 ". En cambio, cifra la población activa española en 185.765 religiosos; 160.000 militares; 1.335 trabajadores de: la administración de justicia (civil y eclesiástica); 40.000 empleados en la administración de la Real Hacienda; 42.350 escribanos, procuradores, agentes y alguaciles; 800 abogados; 42.350 médicos, cirujanos y mancebos; 42.350 estudiantes; 974.719 labradores; 1.936 .902 artesanos, jornaleros, maniobrantes, trajineros y pastores; 42.350 comerciantes y tenderos.

"Bajo de estos presupuestos deducidos de noticias fijas en unos, y de ellas sacada la proporcional a los otros, hallamos que los hombres ocupados son 3.123.256. Los habitantes hábiles son 4.500.614, luego están sin empleo ni destino conocido 1.377 .358 hombres. $\mathrm{Y}$ aun cuando se baje la mitad por los impedidos y enfermos y por los empleos que no estén comprendidos en los ramos expuestos, siempre sale en apoyo de este pensamiento que de hombres hábiles para el trabajo están holgazanes y mendigos 688.679. Contémplese ahora si habría de donde sacar los pastores, labradores y marineros que se necesitarían, más que los que hay actualmente, para que trajinasen con el dinero que está destinado en censos".

La inversión del capital movilizado por los censos consignativos en actividades productivas permitiría la reducción del número de personas sin empleo, la disminución de otros colectivos marginados, la contención del gasto público y privado y la minoración del fraude: "podrían ocuparse muchísimos de los que hoy mendigan, evitando en ellos muchos vicios y ahorrando los crecidos gastos de mantenerlos en los hospicios; y se lograría que las limosnas que éstos defraudan a los verdaderamente necesitados, las diesen los caritativos a las viudas pobres y a los legítimamente impedidos". 
La segunda Demostración le permite a Vizcaíno evaluar el costo económico derivado de la asignación de numerario a las compraventas de censos al quitar. Estima que el capital acensuado permitiría aumentar en un 20 por ciento el producto agrario, cuya obligada tributación procuraría a la Hacienda ingresos adicionales por valor de 575.911.173 reales. Su análisis del coste de oportunidad le lleva a efectuar estas predicciones económicas: cada labrador necesita realizar un desembolso inicial de 7.000 reales; con este capital puede financiar la compra de una yunta de mulas, amortizar los gastos de la alimentación durante un año y costear los aperos de la labor y la simiente. La adquisición de la yunta de mulas le permite sembrar cada año 50 fanegas ( 30 fanegas de trigo y 20 de cebada) que le rendirán 180 fanegas de trigo y 240 de cebada. Con la extrapolación de dichos cálculos predice que los 2.879.555.866 reales, importe global de los capitales colocados en el negocio del censo, podrían facilitar la compra de $\mathbf{4 1 1 . 3 6 5}$ yuntas de bueyes. Evaluando la productividad de cada yunta en 180 fanegas de trigo, se podrían cosechar 74.045 .700 fanegas. Tal volumen de producción generaría beneficios fiscales por importe de 32.909.200 reales al año. Además, las 411.365 yuntas de mulas posibilitarían la recogida de 98.727 .600 fanegas de cebada ( 240 fanegas por yunta), lo cual reportaría a la Hacienda ingresos por valor de 21.939 .460 reales al año.

Con el fin de incrementar los flujos de producción agraria aconseja la ejecución de una política económica basada en estos puntos: supresión de privilegios a los ganaderos, moderación de rentas en los arrendamientos rústicos e intervención en materia de precios y salarios:

"Lo que no tiene duda es que, interim no se quiten los censos, se reformen algunos privilegios de los ganaderos que perjudican a los labradores, no se moderen a lo justo los crecidos arrendamientos que pagan por los terrazgos, y no se haga una tasa general de todas las cosas, salarios y jornales, de modo que queden en una proporción con que el labrador, vendiendo el trigo a 24 reales, saque su coste y proporcionada ganancia, no se podrá conseguir la abundancia apetecida; porque no es posible, ni justo, que el labrador venda el trigo a moderado precio si los demás comestibles, el vestido, el calzado, los jornales y las demás cosas de que necesita tienen subidos valores. Ni parece conforme a la justicia distributiva el que se haya de poner tasa a los granos para que no se vendan con exceso, y que el mercader, ganadero, el zapatero y todos los demás que venden, lo ejecuten sin tasa... y más cuando la experiencia enseña que si por causa de una cosecha se altera el precio del trigo y la cebada, todos los que venden encarecen sus géneros con el pretexto de la carestía del pan y del mayor costo en la conducción".

En la última Demostración Vizcaíno expone los beneficios que resultarían de la inversión del capital acensuado en actividades mercantiles: desde el aumento de la flota naviera hasta la percepción de los fletes "que hoy pagan a los extranjeros". Las reticencias que pudieran mostrar los ahorradores a la hora de colocar sus capitales en negocios comerciales desaparecerían con la creación de un banco público o compañía general: "donde cualquiera pueda poner los caudales que tuviesen en acciones diferentes de a 1000 y más reales, creando para su dirección una Junta de Comerciantes hábiles de todas clases de comercio... y sujetándolos a dar cuenta anual de las utilidades o pérdidas, para que se repartiesen 
las ganancias a prorrata entre los accionistas". En previsión de posibles fraudes se dotaría a la citada institución de un Consejo con personal cualificado que fiscalizase las cuentas y presentase un balance anual.

Vizcaíno Pérez, tras denunciar los perjuicios económicos, sociales y políticos que ocasiona el censo al quitar, propone diversas reglas para erradicar la escasez de pan en España. Todos los años, hacia el mes de marzo, las justicias de los pueblos deberán confeccionar un censo donde se detallen la identidad de los moradores y los niveles de consumo de pan. Así "se sabrá fácilmente cuantas fanegas de trigo se necesitan en cada lugar para el año, regulando a razón de 8 fanegas por persona que corresponde a libra y media de pan por persona en cada un día". La preocupación de Vizcaíno por garantizar el abasto de pan resulta lógica, por cuanto la falta de liquidez planteaba a concejos y ayuntamientos serias dificultades de aprovisionamiento. En tales coyunturas, el recurso al crédito era inevitable, contribuyendo éste al endeudamiento progresivo de las haciendas municipales. Nuestro personaje, conocedor de este problema financiero, proponía la creación de un banco público con un capital inicial de 2.879.555.866 reales procedentes de los censos consignativos. Dicho fondo se destinaría al comercio del cereal y permitiría satisfacer la demanda con creces. Para que el balance anual del banco agrícola no arrojase pérdidas, se le concedería el monopolio del comercio de los granos y se le fijaría un margen de ganancias de 1 real por fanega. Con todas estas medidas se evitaría que el precio del pan ascendiese a más de "siete cuartos y medio", así como el acaparamiento y la especulación.

En síntesis, Vizcaíno Pérez responsabiliza a los censos del injusto reparto de la carga tributaria, de la ociosidad que aqueja a buena parte del tejido social (afirma que si el capital acensuado se invirtiese en actividades productivas se generarían numerosos empleos directos e inducidos) y de la despoblación del país (la supresión de los censos fomentaría los matrimonios y contribuiría al aumento de la población). Tan sólo les reconoce esta utilidad: "la de que con ellos se pueden socorrer los que tienen haciendas, en caso de alguna urgencia o ahogo, sin desapropiarse enteramente de ellas; pero por tan pequeño beneficio, que se puede conseguir de otro modo, como propondré después, no parece que se deben permitir tantos daños, como dejo expuestos y demostrados".

Los Discursos Politicos sobre los estragos que causan los censos concluyen con la propuesta de una serie de remedios para su extinción. Entre las recetas que su autor juzga apropiadas se encuentran la prohibición de retribuir el capital acensuado y la promulgación de una ley que declare nulos los censos y establezca medidas punitivas contra los infractores (27). También aconseja como alternativa la reducción de la tasa de interés del censo al quitar al 1 ó 1,5 por ciento para restar incentivos a sus potenciales compradores. $Y$ para los censos ya suscritos

(27) "Todos estos antecedentes daños cesarían, y se sustituirían por ellos los demostrados beneficios, promulgando S. M. una Ley (que se podía apellidar de la felicidad y restauración de España) en que, declarando extinguidos los censos hasta ahora creados, mande que en lo sucesivo no puedan pedirse ni se paguen con ningún pretexto ni motivo réditos algunos; que no se pueda imponer a censo cantidad alguna en lo futuro; que sean nulas las escrituras que se otorgasen, prohibiendo esta especie de contratos con las más rigurosas penas, así a los escribanos que las autoricen como a los otorgantes que den o reciban el dinero". 
propugna incrementar su interés en un 5 por ciento que se destinaría a la amortización del capital: "que los que tienen sus haciendas acensuadas paguen de réditos un 5 por 100 más cada año a cuenta del capital... v. g., tengo yo un censo de 100 reales de capital, por el que pago anualmente 3 reales; pues desde ahora en adelante pagaré un 6 por 100; el 1 por razón de réditos corriente y los 5 para extinguir el capital. El año siguiente ya no pagaré más que otros 5 reales para extinción del capital y 32 maravedís del rédito correspondiente a los 95 reales que habían quedado de principal. Esta cuenta, aunque parece embarazosa, no lo es, porque en sabiendo la regla de tres, se forma fácilmente diciendo: si por 100 reales, que era el capital del censo, pagué el año primero de esta pragmática 1 por 100, que son 34 maravedís, al siguiente, en que ya el capital no es más que 95 reales, porque el año antes se depositaron 5, pagaré 32 maravedís". Por último, y para no perjudicar los intereses de los actuales censualistas, afirma lo siguiente:

"para que los dueños de los censos no padezcan perjuicios ni pierdan los capitales que desembolsaron, o sus antecesores, acordar y declarar que respecto de que en virtud del contrato de censo no le pueden pedir hasta que el censatario le quiera redimir, desde ahora en adelante, en lugar de réditos, sólo tengan acción a la parte de frutos correspondiente a su capital, percibiéndolos de aquellas fincas sobre que especialmente están impuestos; y a cuyo fin puedan elegir y elijan de ellas las que basten a cubrir el capital y los réditos devengados hasta el día de la publicación de la Ley... que desde el mismo día en que cesen los efectos de los contratos de censos sean dueños propietarios con dominio revocable por 20 años de aquellas posesiones, casas, acciones o predios que hayan elegido; y a prorrata de la cantidad que tengan en el predio, u acción elegida, perciban los emolumentos que produzca, contribuyendo a proporción a los reparos y sufriendo los huecos, descuentos o pérdidas que experimente la alhaja, como dueño de ella".

Antes de concluir, quizá convenga aclarar que el censo consignativo, a pesar de la severa crítica expuesta en las páginas anteriores, constituyó una vía para obtener crédito y sí tuvo efectos positivos sobre la economía castellana (28). Así pudo suceder durante los primeros sesenta o setenta años del Quinientos. Luego, con la llegada de los primeros síntomas de recesión, los censos se convirtieron en

(28) El crédito es un componente esencial de la teoría de la intermediación financiera. "La primera etapa del desarrollo de un sistema financiero puede considerarse como el paso del trueque al uso de dinero mercancía. Aunque este paso libera al intercambio de mercancías de las limitaciones del trueque, por sí mismo no hace nada por el crecimiento de las empresas, porque los únicos fondos disponibles para inversión en capital proceden de la renta actual o de saldos monetarios acumulados previamente por el propio empresario. El desarrollo del crédito, en forma de préstamo directo, permite que los saldos monetarios acumulados por otros sean transferidos al empresario, que de esta manera puede utilizar provechosamente los ahorros de muchas otras personas". Y un instrumento básico de la estructura financiera durante los siglos modernos fue el censo consignativo. Este, a pesar de las críticas, estimuló la inversión productiva "en tiempos en que no existían organizaciones de crédito y penuria de apoyos económicos que posibilitaran la obtención de medios para la 
un factor añadido de crisis para las haciendas campesinas y pasarían de ser los instrumentos de financiación del progreso a convertirse en mecanismos propiciadores de la acumulación territorial (29). Aún así, las inyecciones de capital en activos censales y títulos de la deuda pública consolidada (juros) fue en aumento desde el siglo XVI. Tal vez porque, con independencia de las tensiones inflacionistas o deflacionistas, el préstamo hipotecario garantizado por la tierra era una inversión que ofrecía seguridad y confianza (30). De la importancia del censo al quitar dio testimonio Valle de la Cerda cuando afirmó que en la España de 1618 el negocio censal movilizaba recursos monetarios por valor de 100 millones de maravedís.

realización de sus labores por parte del agricultor". Muchos labradores se vieron en la necesidad de imponer censos sobre sus haciendas para poder costear los gastos de la explotación, abonar el pago de las rentas y saldar las obligaciones tributarias, lo cual maldecian escritores políticos porque consideraban injusto que los censualistas fueran partícipes del producto agrario sin haber colaborado en la sementera ni asumido el riesgo de la adversa climatología; pero al responsabilizar a los censos de la ruina y miseria del agricultor, no "reparaban que toda granjería necesita caudal proporcionado; y prohibit al labrador que tome dinero prestado es imposibilitar el cultivo y sentenciarle a perecer de hambre. Siempre fue la usura la lepra de los campos, y este mal no se cura dificultando, sino facilitando los medios de buscar dinero a menos costa".

DEANE, Ph. y KUPER, J. (Eds.)., Vocabulario básico de economía. Barcelona, 1992, p. 123; VIÑAS y MEY, C., El problema de la tierra en la España de los siglos XVI-XVII. Madrid, 1941, p. 37; COLMEIRO, M., Historia de la Economía Política Española. Edición del Banco Exterior. Madrid, 1988 , p. 77.

(29) VIÑAS y MEY es de esta opinión: "Mientras se mantuvo la prosperidad agricola y sus elevados rendimientos, se superaron las desventajas económicas, jurídicas y sociales del sistema de censos, y aun en cierto modo desempeñaron en ocasiones una función eficaz... Pero cuando sobreviene la depresión y la decadencia cambia la decoración radicalmente.

El empobrecimiento progresivo del campo y del labrador, originado por la desfavorable coyuntura económica en baja de los mercados europeos e indianos, e incluso del propio mercado peninsular al descender el tipo económico general de vida, por el régimen de tasas, el aumento desaforado de los impuestos y demás factores de ruina, produce en la materia que examinamos un doble fenómeno de inevitable lógica económica: el labrador, los cultivadores de tierra, cada vez más necesitados de recursos, tienen que buscarlos por todas las vías, impulsándose el aumento de los censos, y a su vez, disminuida la ganancia y agobiados de cargas, se les va haciendo cada vez más difícil el pago de intereses o del capital, finado el plazo, creciendo los réditos a compás del retraso, y con ello la imposibilidad de pagarlos.

El rigor del contrato hipotecario desarrolla su función, y las fincas acensuadas van cayendo en poder de los "señores de censos""

VIÑAS y MEY, C., op. cit., pp. 35, nota 4, y 49.

(30) SALOMON, N., La vida rural castellana en tiempos de Felipe II. Barcelona, 1982, p. 252. 